\title{
Ethics and Lobbying: The Case of Real Estate Brokerage $^{1}$
}

\author{
David Barker ${ }^{2}$
}

May 25, 2007

${ }^{1}$ I thank the Institute for Ethical Business Worldwide and the Mendoza College of Business, University of Notre Dame for their support. I also thank Robert Audi, Tim Loughran, and Ann Tenbrunsel for their helpful comments and suggestions.

${ }^{2}$ Visiting Scholar, University of Iowa. Email: fdbarker@gsb.uchicago.edu 


\begin{abstract}
Members of licensed occupations benefit from legal standards that limit entry into their professions. Is it ethical for these professionals to give political support to these standards? I examine the case of real estate brokers and find that their educational requirements raise average commissions by one quarter of a percentage point, costing consumers $\$ 5.4$ billion per year without improving the quality of brokerage services. The case raises interesting ethical issues which are difficult to resolve.
\end{abstract}




\section{Introduction}

The code of ethics of the National Association of Realtors (NAR) states:

"Under all is the land. Upon its wise utilization and widely allocated ownership depend the survival and growth of free institutions and of our civilization...Such interests impose obligations beyond those of ordinary commerce. They impose grave social responsibility and a patriotic duty to which REALTORS® should dedicate themselves"

This code suggests that in one of the NAR's most important activities, lobbying federal and state governments on issues affecting real estate brokers, it will support policies that will promote general welfare, not just the welfare of brokers. This stance is consistent with other codes of ethics that have been developed for lobbying. For example, the "Woodstock Principles" (Woodstock Theological Center, 2002) contain the following:

"In deciding whether to undertake an engagement or assignment and in determining what arguments to advance in support of, or in opposition to, a position, lobbyists should weigh the implications of their efforts for the well being of the country as a whole."

Lobbyists face ethical dilemmas when they promote policies that might enrich their clients at the expense of the public. Their alternatives in such a situation are to either decline to support the policy or to concoct specious arguments in favor of the policy, perhaps in combination with financial support for legislators. A difficulty that scholars of ethics face in these situations is separating valid from specious arguments for these policies. If the arguments are specious, then there is a potential ethical problem to study. 
In this paper I examine a particular policy: educational standards for real estate brokers. High educational standards are supported by real estate brokers, who argue that educational standards improve the level of brokerage service and protect the public from poorly trained and/or unscrupulous brokers. Many economists, however, believe that the effect of high educational requirements is to restrict the supply of brokers and thereby raise broker income. Analyzing a variety of state level data, I find evidence that high educational standards raise broker income without improving the quality of brokerage services. The effect of these standards is significant; I estimate that they raise the average brokerage commission by one quarter of a percentage point, costing consumers $\$ 5.4$ billion per year.

Section two reviews previous literature on the effects of occupational licensing. The real estate brokerage industry is described in section three. Section four presents an empirical study of the effects of real estate brokerage licensing restrictions. Ethical implications of these results are discussed in section five.

\section{Literature Review}

A recent survey (Kleiner 2000) of economic literature on occupational licensing begins with Adam Smith's discussion of craft apprenticeships. Smith argued that long apprenticeships do not improve quality or honesty, and that their real purpose is to restrain competition and raise prices. Kleiner (2000) observes that the effect of occupational licensing was a popular topic for economists until late in the 20th century. In recent years economists have neglected the topic, in spite of the fact that the number of workers in licensed occupations has grown. Kleiner (2000) points out that there are more workers in licensed occupations than workers who are members of unions or are directly affected by the minimum wage, yet occupational licensing has, in recent years, received far less 
attention in the economics literature.

Milton Friedman's Ph.D. dissertation dealt with the effects of occupational licensing, and was later published. Friedman and Kuznets (1945) wrote

"In all professions, there has developed in the last few years an aristocratic, or at least a restrictive movement which, in a sense, is reminiscent of the medieval guilds."

Stigler (1971) argued that regulation should be considered like any other good or service, with industries as the demanders of regulatory protection, and governments as the suppliers. He found that professions with lower costs of political mobilization were more likely to be licensed. This analysis was extended by Peltzman (1976). Maurizi (1974) found evidence that pass rates on licensing examinations are manipulated to control the supply of licensed professionals. Benham (1972) found evidence that advertising restrictions, supported by the industry, increased prices of eyeglasses, and Benham and Benham (1975) found that other regulations that raised the price of eyeglasses were more common in states with strong optometrist trade associations. Maurizi, Moore, and Shepard (1981) examined the competing interests of ophthalmologists, optometrists, and opticians, and found that strong professional organizations lead to regulations favoring particular groups.

The stated purpose of licensing is to improve the quality of services provided by professions, but quality is often difficult to measure. One of the earliest attempts to measure the simultaneous effects of licensing on quality and price was Carroll and Gaston (1981). These authors examined the effects of different state licensing standards for electricians, dentists, plumbers, optometrists, sanitarians, real estate agents, and veterinarians. For each profession, their results showed that restrictive licensing standards lowered the number of professionals and that lower numbers of professionals per capita 
appeared to lower the quality of service.

Following Friedman and Kuznetts (1945), Carroll and Gaston (1981) explain several theoretical reasons why licensing might lower, rather than raise quality levels for a profession. If licensing raises prices, then consumers will have an incentive to either perform services for themselves or reduce their consumption of services. In the case of electricians, for example, Carroll and Gaston (1981) measured quality of electrical services in a state by the rate of death by electrocution. If licensing standards are high in a state, then homeowners will be more likely to wire their own houses instead of calling for an electrician, and are more likely to electrocute themselves. Kleiner (2000) gives an example of people performing root canals on themselves because dentists were too expensive.

Peltzman (1987) examines data from countries with different drug laws and finds that requiring prescriptions for the purchase of medication does not reduce mortality from poisonings or disease. This result calls into question the practice of licensing pharmacists.

Other reasons that quality might be hurt by licensing include highly trained professionals spending time on tasks which do not require high levels of training, but which cannot legally be performed by unlicensed people. Licensed professionals will then have less time to devote to tasks that require their training. Another possibility is that firms performing services might compete with each other on quality as well as price. If licensing reduces competition, then it might cause firms to reduce the level of quality of their services.

It is also possible that the overall effect of licensing on quality would be zero if the effects described above were offset by the quality improving effects of required training and continuing education. Kleiner and Kudrle (2000) find that the dental health of Air Force recruits is no better (and no worse) in states with tough dentist licensing stan- 
dards, but that earnings of dentists are significantly higher in these states. Federman, Harrington and Krynski (2006) find that high licensing standards reduce the ability of Vietnamese immigrants to enter the manicuring business. They do not test effects on quality directly, but present reasons to doubt that these standards enhance quality.

Carroll and Gaston (1981) use duration of vacancy before sale to measure the quality of real estate brokerage services. This measure is criticized by Johnson and Loucks (1986), who argue that time on the market is determined by many factors unrelated to the quality of a broker which are not controlled for in Carroll and Gaston (1981). Another problem is that the results concerning real estate agents reported by Carroll and Gaston (1981) have only borderline statistical significance.

Two papers, Johnson and Loucks (1986) and Shilling and Sirmans (1988) measure the quality of real estate services by using complaints to state real estate boards. Their methodology of simultaneous equations determining quality and price is similar to that of Carroll and Gaston (1981). Both papers find that stricter licensing standards reduce the number of complaints, but the papers differ on the effect of licensing standards on broker income. Johnson and Loucks (1986) find weak evidence that strict standards lower the number of brokers, but do not find that strict standards raise broker income. Shilling and Sirmans (1988) find "significant anticompetitive side-effects" of restrictive licensing. Johnson and Loucks (1986) acknowledge that their study suffers from a lack of time series data and from low quality data on broker earnings. Broker earnings are measured as state median earnings from the Census Department classification "Other Finance and Real Estate" multiplied by the state median house price. It is not entirely clear why they multiply income by house prices. Their explanation is that "This captures the multiplicative nature of how real estate earnings are derived - as commissions based on sales prices."

Shilling and Sirmans (1988) estimate a two equation simultaneous system with the 
number of complaints and the examination pass rate as the two dependent variables. A lower pass rate lowers the number of complaints, but excess demand for licenses, measured as the ratio of applicants to the number of licensed agents, lowers the examination pass rate. In other words, real estate boards appear to be using the examination pass rate as a tool to limit supply.

Overall, the economics literature on occupational licensing provides clear evidence that licensing raises prices and the incomes of licensed professionals in a variety of occupations, but the evidence on quality is less clear. In the case of real estate brokerage, the evidence on quality and income is mixed, but papers on the subject have had significant data limitations, and none have been published since the 1980s. Since that time, better data have become available, changes in technology have led to new policy questions regarding the licensing of real estate brokers, and recent increases in real estate sales volume and prices have increased potential broker income. For all of these reasons, it seems appropriate to reexamine the issue of whether strict licensing standards are in the public interest.

Previous academic research in the field of business ethics has generally taken the position that lobbying is unethical if it is an attempt to benefit a particular industry or group at the expense of the general public. Keffer and Hill (1997) write that "when lobbying results in the subordination of the needs of the larger community to the needs of special interests, a correction should occur." Gowthorpe and Amat (2005) go further in their discussion of accounting firms lobbying for regulatory changes that are favorable to themselves, writing that these activities "can be regarded as morally reprehensible. They are not fair to users, they involve an unjust exercise of power, and they tend to weaken the authority of accounting regulators."

Economists have been less interested in explicit consideration of ethics than have scholars in other fields, preferring objective rather than normative analysis of policies 
and human behavior. (Friedman 1953, McCloskey 2007) They do, however, tend to have a negative view of "rent seeking", defined as pursuing wealth in ways that do not add to the productive capacity of society as a whole. (Krueger 1974) Lobbying is usually viewed as a rent seeking activity. In contrast, Becker (1976) takes preferences for government redistribution of income as given and argues that the methods chosen to do so by the political system tend to be the most efficient available. In this view, lobbying is simply a part of the political and economic system that leads to an efficient allocation of resources given preferences, and is no more and no less virtuous than other parts of the system.

Political scientists have also long viewed lobbying with suspicion, but some recent work takes a different view. Hall and Deardorff (2006) for example, see lobbying as a "legislative subsidy", assisting legislators already in support of industry goals, rather than persuading or bribing them. These authors argue that their model requires a significant reappraisal of the ethical implications of lobbying.

\section{The Real Estate Brokerage Industry}

Every building has unique characteristics and every parcel of land has a unique location. Unlike commodity investors, real estate investors must spend considerable time and money gathering information about each individual asset that they consider purchasing. Investors often rely on real estate brokers to provide this information, and sellers rely on brokers to connect them with buyers. Brokers are usually hired by sellers, and are paid a percentage of the sale price of the real estate, although buyers sometimes hire brokers on their own. ${ }^{1}$ The NAR estimates that licensed brokers are involved in $86 \%$ of all single family home sales in the U.S.

Each state in the U.S. requires real estate brokers to be licensed. Individuals may

\footnotetext{
${ }^{1}$ Levitt and Syverson (2005) present evidence that brokers sometimes use their informational advantage to benefit themselves at the expense of their clients.
} 
sell or rent their own property without a license, but any third party broker operating without a license is in violation of the law, and in many states has committed a felony. Real estate offices may hire assistants to perform some routine tasks, such as answering telephones, making keys, or placing signs on properties, but unlicensed people are not allowed to perform services such as discussing material details of a property or transaction with a customer, showing property, or collecting money.

In most states there are two kinds of real estate broker licenses: salesperson and broker. A licensed salesperson is able to earn fees from facilitating real estate transactions, but must work under the supervision of someone with a full broker's license. In order to obtain a salesperson's license, candidates must complete state approved educational courses and pass an examination. The course requirements for a salesperson range from 18 hours in Rhode Island to 150 hours in Texas. A broker's license requires a number of years spent as a salesperson, more coursework, and another examination. For example, becoming a full broker in Texas requires a total of 840 hours of classroom instruction, while Alaska requires only 35 hours. Experience requirements range from zero in several states to five years in Delaware. In every state except New Jersey, maintaining a salesperson's or brokers license requires attendance at continuing education courses, with requirements ranging from 2 hours per year in Michigan to 24 hours per year in Arizona.

Educational and experience requirements do not change frequently, but changes are generally in the direction of raising standards. ${ }^{2} \mathrm{~A}$ few states in recent years have eliminated the salesperson's license, requiring all licensees to meet the stricter requirements of brokers. ${ }^{3}$

\footnotetext{
${ }^{2}$ Texas recently passed H.B. No. 3507, which raised educational standards for real estate licenses. California Assembly Bill 2429 would do the same. Florida Senate Bill 466 would raise standards for real estate appraisers. Florida recently made practicing without a real estate license a felony.

${ }^{3}$ Colorado made this change in 1997. Oregon and South Dakota have also combined their license types.
} 
Broker education requirements increase the cost of obtaining a license, which might reduce the number of brokers, which in turn might raise the prices that brokers are able to charge. In recent years rising house prices and sales volumes have increased the nationwide demand for brokers. Even though the number of brokers has risen, education requirements might have slowed this increase, so that the number of brokers has not risen as much as it otherwise might have done. On the other hand, broker education programs might increase the quality of the services brokers provide. Another effect that is possible is the creation of camaraderie in the profession, which might help brokers to resist the temptation to cut their commissions.

There are currently approximately 1.5 million active licensed salespersons and approximately 650,000 active licensed brokers in the U.S. The numbers are growing rapidly; in 2000 there were approximately 1 million active licensed salespersons and 570,000 brokers. They are represented by the largest trade association in the U.S., the National Association of Realtors (NAR), with 1.2 million members. The NAR is currently the third largest political donor at the federal level in the U.S., contributing over $\$ 4$ million in each of the 2002 and 2004 election cycles. The NAR's contributions are nearly evenly split between Democrats and Republicans. In addition, the NAR is active in state and local politics, with a strong interest in issues that affect the brokerage industry. A Federal Trade Commission Report in 1983 quoted a state official as saying that "virtually no proposed legislation relating to real estate has a chance of passage unless it is approved by the state association of realtors." (Nadel 2006)

Perhaps the most interesting and puzzling aspect of real estate brokerage is the persistence of high, fixed percentage commissions. In the 1940s, the code of ethics of the NAR stated that "the schedules of fees established by the various Real Estate Boards are believed to represent fair compensation for services rendered in their communities and should be observed by every realtor." The United States Supreme Court found 
in $1950^{4}$ that this code violated the Sherman Act, even though the NAR imposed no explicit penalties on brokers who undercut the recommended commission rate. The 1950 decision applied only to Washington D.C., however, leaving open the question of whether the Interstate Commerce Clause of the U.S. Constitution allowed the federal government to enforce the Sherman Act against local real estate brokers. Local chapters of the NAR continued to promote standard 6-7\% commission rates until a series of lawsuits during the 1960s and 1970s by the U.S. Justice Department resulted in fines and probation for some real estate brokers. ${ }^{5}$ Another Supreme Court decision in $1980^{6}$ finally established that real estate brokerage qualified as interstate commerce.

Since 1980, real estate brokers have been careful to avoid the appearance of collusion. Commissions, however, have remained high and remarkably uniform. A Federal Trade Commission report in 1983 (Federal Trade Commission 1983) found that most brokers received commissions of $6 \%$ or $7 \%$. An analysis (Hsieh and Moretti 2003) of data from the Consumer Expenditure Survey from 1980 to 1998 comes to similar conclusions. One paper (Sirmans and Turnbull 1997) argues that commissions are not fixed, and finds variations over a housing market cycle of approximately one quarter of one percentage point (0.0025 of the purchase price of a house).

Nadel (2006) discusses some of the reasons why high fixed percentage commissions have survived. The primary reason appears to be the political power of the NAR, which encourages state legislatures and real estate commissions to protect traditional brokerage practices. In addition to licensing requirements discussed above, some states prohibit commission rebates and require consumers to purchase a larger bundle of services from brokers than they might otherwise choose. (Nadel 2006)

\footnotetext{
${ }^{4} 339$ U.S. 485 (1950).

${ }^{5}$ The Justice Department recommended prison terms in some cases. One broker was sentenced to prison after announcing at a speech at an industry dinner that he would raise his commissions from $6 \%$ to $7 \%$. The sentence was later reduced to probation. Boston Globe, May 17, 1992 p. A1.

${ }^{6} 444$ U.S. 232.
} 
New competition from real estate brokers using low cost Internet advertising and non-licensed companies that allow individuals selling their houses without a broker to advertise on the Internet have the potential to lower commission rates. This new competition led the NAR to attempt to limit the ability of brokers to post listings on the Internet, which led to another Justice Department lawsuit against the NAR in 2005. There is some evidence that commissions have recently declined. For example, a recent survey (Real Trends 2006) found that nearly 50\% of home sellers using a broker paid less than a $5 \%$ commission. The evidence for a reduction in commissions is limited, however, and some economists (Nadel 2006) have questioned whether commissions have actually declined in recent years.

\section{Testing the Effect of Licensing Restrictions}

\subsection{Model}

Measuring the effect of real estate broker licensing restrictions requires an analysis of the supply and demand for brokers. It seems reasonable to expect that demand for brokers will decline with increases in broker pay and that the supply of brokers will rise with increases in pay. If a typical broker in a state earns more, holding transaction volume and other factors constant, then homeowners in that state will demand fewer brokerage services. Similarly, if brokers earn more in a state, then more people in that state will want to become brokers.

Licensing restrictions can be modeled as shifting the supply curve for brokers. Licensing restrictions raise the cost of obtaining a license, so for any given rate of pay of brokers, higher licensing requirements will mean fewer brokers. If the demand curve for brokers is downward sloping, then shifting the supply curve of brokers to the left will 
lower the equilibrium quantity of brokers in the market and raise broker pay.

Data on prices and quantities are often available in various markets, but estimating supply and demand curves is not a simple task. The problem is that each observed price/quantity pair is assumed to represent an equilibrium - an intersection of supply and demand. We cannot simply perform regression analysis on these points because we are not sure of whether we are measuring the supply or the demand curve.

A two equation system for estimating supply and demand in the brokerage market is shown below. The number of brokers is given by $B$, and the income of brokers is $I$. Exogenous variables in the demand equation are given by $X_{d}$. The strength of licensing restrictions is given by $L$, and other exogenous variables in the supply equation are given by $X_{s}$.

$$
\begin{aligned}
& \text { Demand: } \quad B=\alpha_{1}+\alpha_{2} I+\alpha_{3} X_{d} \\
& \text { Supply: } \quad B=\beta_{1}+\beta_{2} I+\beta_{3} L+\beta_{4} X_{s}
\end{aligned}
$$

In this system, we expect $\alpha_{2}$ to be negative, indicating a downward sloping demand curve, and $\beta_{2}$ to be positive, indicating an upward sloping supply curve. If educational requirements and other licensing restrictions reduce the supply of brokers, then we would expect the coefficient $\beta_{3}$ to be negative.

If these expectations prove to be correct, then the model will imply that raising licensing standards will shift the supply curve to the left, lowering the equilibrium quantity of brokers and raising the income (price) of brokers. The amount that income is raised will depend on the slope of the demand curve with respect to price.

Anecdotal evidence suggests that industry professionals see links between high educational standards and fewer brokers. Jeff Foster, Deputy Director of the Colorado Real 
Estate Commission, was quoted ${ }^{7}$ as follows:

"We have close to 196 hours (in educational requirements) to be broker associate. We sure saw a drop off in our applicants because we did raise the bar and there were less applicants."

Foster did not see evidence that complaints had fallen as a result of higher educational requirements. The link between the number of brokers and commissions was also discussed in Hsieh and Moretti (2003), a paper that was widely discussed in the popular press and the brokerage community.

A reasonable question to ask about this model specification is whether licensing requirements should be treated as exogenous to the system. Licensing requirements, consisting mostly of educational and experience requirements, do not change frequently. The requirements are the result of political compromises between industry lobbyists, consumer groups, and others as well as unique historical circumstances of each state. If the requirements changed frequently in response to changing market conditions then they would clearly be endogenous, but for the time period examined in this paper it seems reasonable to treat them as exogenous.

It would be interesting to model the quality of brokers as an endogenous variable in this system. A third equation could be added with quality as the dependent variable and licensing requirements as an independent variable. Quality might shift the demand curve, since demand at any given price should be higher if quality is higher. Shilling and Sirmans (1988) and Johnson and Loucks (1986) attempted to model quality in a two equation system, but they did not have accurate data on income that would have allowed them to estimate a supply and demand system. The best available data for measuring broker quality is state level data on complaints against brokers, but unfortunately these

\footnotetext{
${ }^{7}$ Realty Times, May 10, $2002<$ http://realtytimes.com/rtapages/20020510_icensure2.htm> .
} 
data are not uniformly reported across states, making it difficult to add quality to the supply and demand system.

\subsection{Data}

The quantity of real estate brokers in each state is measured in this paper as the number of active licensed brokers and salespeople. Because the definitions of brokers and salespeople differ from state to state, I use the total instead of analyzing the two categories separately. The number of licensed brokers in each state is available from the Association of Real Estate License Law Officials (ARELLO). The number of brokers is divided by state population. ARELLO also provides information on state licensing standards, complaints, and other aspects of real estate brokerage.

The price of real estate brokers is measured as the average income as reported by the Occupational Employment Statistics (OES) program of the Bureau of Labor Statistics. The program reports income by state for over 800 occupations. Income is reported for both salespersons and brokers, but data on brokers are missing for many states, so mean salesperson income is used. Income figures are adjusted for inflation over time using the Consumer Price Index.

Housing sales data are from the National Association of Realtors, and house price data are from the Office of Federal Housing Enterprise Oversight. State GDP data are from the Bureau of Economic Analysis, and other state characteristics are from the Census Department.

Table 1 contains a summary of data definitions, and Table 2 provides descriptive statistics for the dataset. The endogenous variables, Income and Brokers, vary considerably from state to state. The average income for salespersons was over $\$ 100,000$ per year in Hawaii in 2000, but less than $\$ 25,000$ in Mississippi and Arkansas. More than 
$1 \%$ of the populations of Florida, Massachusetts, New Hampshire, California, and the District of Columbia are active brokers or salespersons, but the fraction in South Dakota is less than $\frac{1}{4}$ of $1 \%$. Variation is also significant for many of the exogenous variables. For example, in 2005, a typical homeowner in Nevada was more than twice as likely to sell a house than a typical homeowner in Michigan.

\subsection{Results}

Results for the two equation system are shown in Table $3{ }^{8}$ Encouragingly, the estimated demand curve slopes down, and the supply curve slopes up. All of the exogenous variables except Renter in the demand equation have the expected signs. Growth in state GDP per capita has a positive coefficient, although it is not statistically significant. Higher per capita state GDP raises the demand for brokers, as does living in urban areas. Shorter times between moves raises demand, as does the average house price. Population growth raises demand, although this variable is only statistically significant at the $9 \%$ level. The percentage of the population in rental housing has a positive coefficient, although it is not statistically significant.

The supply equation contains the variables on licensing restrictions. All three measures, hours of pre-licensing courses, years of experience before becoming a broker, and annual continuing education requirements have negative coefficients, although hours of pre-licensing courses is not statistically significant. The other two measures, however, are significant at a very high level of confidence. Poor weather conditions in a state appear to discourage people from becoming brokers. ${ }^{9}$

\footnotetext{
${ }^{8}$ The results discussed in this section were obtained using three stage least squares. Two stage least squares and limited information maximum likelihood estimation produced very similar results.

${ }^{9} \mathrm{~A}$ referee suggested that good weather might be correlated with high demand for second homes, which would increase demand for brokers. The measure of poor weather I use, the number of days of precipitation per year, appears to have a very low correlation with the prevalence of second homes. Including the percentage of HMDA loans in a state that are to non-occupants as a variable in the demand equation did not significantly affect the results.
} 
The estimates shown in Table 3 suggest that the total effect of educational and experience requirements amounts to $\$ 5.4$ billion per year in losses to consumers. Without educational and experience requirements, the typical commission on a house sale would go from $6 \%$ to $5.76 \%$. Details of these calculations can be found in the Appendix.

Previous studies have used data on complaints filed against brokers to measure broker quality by state. These data are available from ARELLO, but complaints do not seem to be reported in a uniform manner from state to state. For example, Alabama reported 2,924 complaints from the public in 2004, while Missouri, with a larger population than Alabama, reported 184. As a preliminary attempt to investigate these data, I tried to identify states with similar reporting methods by eliminating states with large numbers of complaints as a fraction of house sales.

Table 4 shows the results of a simple regression on the remaining complaint data. The dependent variable is the number of complaints filed as a percentage of the number of house sales. States with high urban populations and rapidly growing populations have more complaints, while states requiring bonding and errors and omission insurance have fewer complaints. Educational requirements for brokers appear to have no statistically significant effect on complaints. The t-statistics on prelicensing, experience, and continuing education are all less than one and do not have consistent signs.

Overall, the empirical results suggest that educational requirements for brokers restrict supply and raise the income of brokers, while there is no evidence that these requirements improve the quality of brokerage services.

\section{The Ethics of Lobbying}

The previous section demonstrates a high probability that strict education and experience licensing requirements for real estate brokers raise broker income without improving 
the quality of brokerage services. Suppose that brokers wish to lobby state governments to increase educational requirements. If the results of the previous section are valid and known, would this lobbying campaign be ethical?

In order to answer this question, it may be useful to divide standards of conduct into three categories: legal, ethical, and admirable. ${ }^{10}$ Legality is the lowest standard of conduct, but also the easiest to define. Although there are ambiguities in laws, there are well accepted methods of interpreting them and an accepted structure of courts to provide definitive interpretations when needed. Ethics, the next standard of conduct, is stricter than legality, but is harder to define. Competing ethical standards make it difficult to decide exactly what conduct is ethical. Admirability is the highest standard of conduct, but also the most ambiguous. Individuals have very different ideas of what conduct is admirable.

Behavior of spouses in marriage provides an example of the application of these standards. Physical spousal abuse is illegal in all U.S. states. Refraining from such conduct meets the very low standard of legality. Engaging in adultery is legal in many jurisdictions, but is, according to most ethical systems, unethical behavior. Giving a spouse an expensive birthday present may be admirable, but it is not required by ethical standards. Standards of admirability vary considerably, so that many people who admire thrift over generosity might think that refraining from expensive gift-giving is admirable.

Certain activities of brokers have been found to be illegal in the past, but lobbying for higher educational standards for real estate brokers is clearly legal. Legislators in the future might choose to limit the activities of lobbyists, making certain kinds of advocacy illegal, but the lobbying activities of brokers currently meet the lowest of our standards of conduct.

Real estate brokers asking regulators to impose higher educational standards on

\footnotetext{
${ }^{10}$ I thank Robert Audi for suggesting these categories.
} 
themselves might, at first, seem admirable. If the analysis of the previous section is valid, however, most people would probably agree that such lobbying is less than admirable, particularly those who have paid real estate commissions or who have been excluded from the real estate brokerage profession by educational or experience restrictions.

If lobbying is legal, but less than admirable, the question of ethics remains. Plausible ethical codes might simply require adherence to contracts and avoidance of dishonesty and coercion, and by these codes lobbying for higher educational standards would be ethical. The plausibility of applying these codes in this situation is reduced considerably, however, by the fact that the NAR has adopted a more stringent code of ethics. Given that this code was voluntarily adopted it seems reasonable to use it to judge the ethics of brokers.

The NAR's code of ethics is essentially Kantian. The "obligations beyond those of ordinary commerce" and "social responsibility" referred to in the code are similar to the categorical imperative which would require that each industry abandon regulatory advantages that do not create net benefits for society. While it can be argued that competition and profit maximizing behavior lead to net benefits in an unregulated market, the same is not necessarily true in a regulated market. The analysis of this paper suggests that restrictive licensing benefits existing brokers, since their incomes are increased. Consumers are hurt, since they pay higher prices with no increase in quality. Potential brokers are also hurt, since many are excluded from the profession. As in any restriction of supply, the total losses exceed the gains; in other words, there are deadweight losses to society. If every industry refrained from regulatory supply restrictions, society would, under this analysis, clearly be better off and so Kantian ethics requires individual industries to refrain from the pursuit of these restrictions.

A positive, rather than normative approach to the ethics of lobbying by brokers would be to use their actions to determine their true code of ethics. In other words, if 
the actions of brokers contradict their stated code of ethics, then this is not their real code of ethics. According to Plato, Socrates held that people cannot knowingly do wrong - if they truly believed that some action was wrong, then they would not do it. Taking an action is evidence that a person does not truely believe that it is wrong. A person might later discover facts or ideas that would cause them to decide that their own past action was wrong, but at the time the action was taken they must have believed it to be right.

By this reasoning, brokers either do not believe their own code of ethics, or they are unaware of or disagree about the effects of licensing restrictions. It is possible that if they were convinced that higher educational standards raise broker income at the expense of their customers that they would stop lobbying for them. It seems unlikely, however, that broker organizations, some of which are large and sophisticated and employ staffs of economists, would be unaware of the effects of policies that they advocate.

Some economists who study regulation believe that appealing to ethical arguments is unlikely to change political behavior. Stigler (1971) argued that it is pointless to expect the behavior of regulators or regulated industries to be in the public interest.

"The idealistic view of public regulation is deeply imbedded in professional economic thought. So many economists, for example, have denounced the ICC for its pro-railroad policies that this has become a cliche of the literature. This criticism seems to me exactly as appropriate as a criticism of the Great Atlantic and Pacific Tea Company for selling groceries, or as a criticism of a politician for currying popular support. The fundamental vice of such criticism is that it misdirects attention: it suggests that the way to get an ICC which is not subservient to the carriers is to preach to the commissioners or to the people who appoint the commissioners. The only way to get a different commission would be to change the political support 
for the Commission, and reward commissioners on a basis unrelated to their services to the carriers."

Some of the regulation criticized by Stigler and other economists has changed, but not usually, as Stigler suggested, by changing the reward structure of commissioners. Instead, as in the case of the ICC, entire regulatory structures have been abolished. Peltzman (1976) predicts that this kind of revolution will occur only when the costs of political organization by an industry or profession exceed the benefits, or when political organization by those hurt by regulatory policy becomes possible. Becker (1976), as noted earlier, goes even further, doubting that there are efficiency gains to be made by pushing for political "reforms".

\section{Conclusion}

The empirical results of this paper suggest that educational and experience standards for real estate brokers raise broker income, raising average commissions by one quarter of a percentage point and costing consumers $\$ 5.4$ billion per year without improvements in the quality of brokerage services. Real estate brokers support and lobby for these standards, raising ethical questions.

The Kantian ethical standard of the NAR's published code of ethics appears to be violated by real estate broker's political support for licensing restrictions. Whether this violation is something to be concerned about, however, is a difficult question. Economists such as Stigler, Peltzman and Becker argue that this behavior is to be expected and that changes are unlikely to improve economic efficiency.

Future research might examine the lobbying practices of other industries. Do other industries support policies that appear to be admirable but actually benefit the industries at the expense of the public? Do these industries have published codes of ethics that 
proscribe this behavior? If industries can be identified that do not lobby for political favors, it would be interesting to discover whether this is because of inherent difficulties in organizing the industry or whether there is an actual ethical choice being made.

\section{Appendix}

This Appendix presents details of the calculations of the effects of licensing restrictions. Coefficient estimates from the system of equations in section 4.1 are shown in Table 3. To obtain an idea of the magnitude of these effects, consider an increase of one hour in the annual continuing education requirement. According to the supply equation, this will decrease the supply of brokers as a fraction of the population by 1.48 basis points. Inverting the demand equation to obtain income as a function of the number of brokers gives a coefficient of -0.159. Multiplying these values together gives an estimate of an increase of $\$ 235$ in average annual broker income for each one hour increase in continuing education requirements. Similarly, adding one year of experience as a requirement for obtaining a full broker's license adds $\$ 852$ in annual broker income. Adding an hour of pre-licensing coursework adds only $\$ 2$ in annual broker income. This difference is probably due to the fact that continuing education is required every year during a broker's career, while the pre-licensing requirements must only be done once, and at a time when the value of the applicant's time is presumably lower than it is later in a career.

Assuming that there are no offsetting benefits to experience and continuing education requirements, welfare losses to consumers can be approximated by multiplying the change in income caused by these requirements in each state by the number of brokers in each state. The result of this calculation is an estimate of $\$ 5.4$ billion per year in losses to consumers. 
A rough calculation of the effect this has on the typical house commission can be obtained as follows. Let $H$ equal the percentage of the value of U.S. privately owned real estate that is owner occupied residential property. $S$ equals the number of sales and $P$ equals the mean price of owner occupied homes in 2005. $C_{r}$ equals the commission percentage on owner occupied homes, and $C_{c}$ equals the commission percentage on commercial property. Assume that the effect of licensing restrictions is the same for residential and commercial property. Then the total of all commissions paid on real estate will be $P S\left(C_{r}+C_{c} \frac{1-H}{H}\right)$. According to the NAR, $P$ is $\$ 266,600$ and $S$ is $7,075,000$. If $H$ is $0.63, C_{r}$ is 0.06 , and $C_{c}$ is 0.02 then the total is approximately $\$ 135$ billion. The estimated effect of educational requirements on commissions is $\$ 5.4$ billion, or $4 \%$ of the total. Another way to express this is to say that without educational and experience requirements, the typical commission on a house sale would go from $6 \%$ to $5.76 \%$.

The actual effects of licensing might be much greater than this estimate, since the model only estimated the variable cost of additional hours of educational requirements, not the fixed costs of license application itself. Since every state in the U.S. requires licensing there is no way to estimate this effect. In particular, the fixed costs of licensing discourage part-time or one-time brokers. For example, in the absence of licensing, an individual who knows a seller and a potential buyer might bring them together for a fee, but might not otherwise practice real estate brokerage. Of course, the estimate also does not include the effects of other anti-competitive actions of brokers, such as those which led to the 2005 lawsuit by the U.S. Department of Justice or those described in Nadel (2006). Adding information on states that prohibit commission rebates, for example, suggests that in these states commissions are another $3 \%$ higher than they would be if rebates were allowed. 


\section{References}

Becker, Gary. 1976. Toward a More General Theory of Regulation: Comment. Journal of Law and Economics, 19, 245-248.

Benham, Lee. 1972. The Effect of Advertising on the Price of Eyeglasses. Journal of Law and Economics, 15, 337-352.

Benham, Lee, \& Benham, Alexandra. 1972. Regulating Through the Professions: A Perspective on Information Control. Journal of Law and Economics, 18, 421-427.

Carroll, Sidney, \& Gaston, R.J. 1981. Occupational Restrictions and Quality of Service Received: Some Evidence. Southern Economic Journal, 47, 959-976.

Eisenpress, Harry. 1962. Note of the Computation of Full-Information MaximumLikelihood Estimates of Coefficients of a Simultaneous System. Econometrica, 30, 343-348.

Epple, Dennis, \& McCallum, Bennett. 2006. Simultaneous Equation Econometrics: The Missing Example. Economic Inquiry, 44, 374-384.

Federal Trade Commission, a. 1983. The Residential Brokerage Industry. Washington: Federal Trade Commission.

Federman, Maya, Harrington David, \& Krynski, Kathy. 2006. The Impact of State Licensing Regulations on Low-Skilled Immigrants: The Case of Vietnamese Manicurists. American Economic Review, 96, 237-241.

Friedman, Milton. 1953. Essays in Positive Economics. Chicago: University of Chicago Press.

Friedman, Milton, \& Kuznets, Simon. 1945. Income from Independent Professional Practice. New York: National Bureau of Economic Research. 
Gowthorpe, Catherine, \& Amat, Oriol. 2005. Creative Accounting: Some Ethical Issues of Macro- and Micro-Manipulation. Journal of Business Ethics, 57, 55-64.

Hall, Richard, \& Deardorff, Alan. 2006. Lobbying as Legislative Subsidy. American Political Science Review, 100, 69-84.

Hsieh, Chang-Tai, \& Moretti, Enrico. 2003. Can Free Entry be Efficient? Fixed Commissions and Social Waste in the Real Estate Industry. Journal of Political Economy, $111,1076-1122$.

Johnson, Linda, \& Loucks, Christine. 1986. The Effect of State Licensing Regulations On The Real Estate Brokerage Industry. American Real Estate and Urban Economics Association Journal, 14, 567-582.

Keffer, Jane, \& Hill, Ronald. 1997. An Ethical Approach to Lobbying Activities of Businesses in the United States. Journal of Business Ethics, 16, 1371-1379.

Kleiner, Morris. 2000. Occupational Licensing. Journal of Economic Perspectives, 14, $189-202$.

Kleiner, Morris, \& Kudrle, Robert. 2000. Does Regulation Affect Economic Outcomes? The Case of Dentistry. Journal of Law and Economics, 43, 547-582.

Krueger, Anne. 1974. The Political Economy of the Rent-Seeking Society. American Economic Review, 64, 291-303.

Levitt, Steven, \& Syverson, Chad. 2005. Market Distortions When Agents are Better Informed: The Value of Information in Real Estate. National Bureau of Economic Research. Working Paper 11053.

Maurizi, Alex. 1974. Occupational Licensing and the Public Interest. Journal of Political Economy, 82, 399-413. 
Maurizi, Alex, Moore Ruth, \& Shepard, Lawrence. 1981. Competing for Professional Control: Professional Mix in the Eyeglasses Industry. Journal of Law and Economics, 24, 351-364.

McCloskey, Deirdra. 2007. Good Old Chicago and Ethics. Presentation, History of Economics Society Meetings, Chicago.

Morgan, Mary. 1990. The History of Econometric Ideas. Cambridge: Cambridge University Press.

Nadel, Mark. 2006. A Critical Assessment of the Standard, Traditional, Residential Real Estate Broker Commission Rate Structure. AEI-Brookings Joint Center for Regulatory Studies. Publication 06-28.

Peltzman, Sam. 1976. Toward a More General Theory of Regulation. Journal of Law and Economics, 19, 211-240.

Peltzman, Sam. 1987. The Health Effects of Mandatory Prescriptions. Journal of Law and Economics, 30, 207-238.

Real Trends, a. 2006. Consumer Tsunami. <http://realtrends.com/go/>.

Savin, Gene. Two-Stage Least Squares Estimator and the k-Class Estimator. <http: www.biz.uiowa.edu/faculty/gsavin/papers/two-state2SLS\%20FinalII.doc>.

Shilling, James, \& Sirmans, C.F. 1988. The Effects of Occupational Licensing on Complaints Against Real Estate Agents. Journal of Real Estate Research, 3, 1-9.

Sirmans, C.F., \& Turnbull, Geoffrey. 1997. Brokerage Pricing Under Competition. Journal of Urban Economics, 41, 102-117.

Stigler, George. 1971. The Theory of Economic Regulation. The Bell Journal of Economics and Management Science, 2, 3-21. 
Theil, Henri. 1953. Repeated Least Squares Applied to a Complete System. The Hague: Central Planning Bureau. Mimeo.

Zellner, Arnold. 1962. An Efficient Method of Estimating Seemingly Unrelated Regressions and Tests for Aggregation Bias. Journal of the American Statistical Association, 57, 348-368. 
Table 1: Variable Definitions.

\begin{tabular}{ll}
\hline Variable & Definition \\
\hline Income & Income of salespersons in thousands of 2005 dollars. \\
Brokers & Active brokers and salespersons, 1/100s of 1\% of state population. \\
GDPGr & Real growth in state GDP over past year. \\
GDPPC & State GDP per capita in thousands of 2005 dollars. \\
Urban & Percentage of population in urban areas. \\
MoveTime & Years per house sale in state. \\
Price & Mean price of single family house in thousands of 2005 dollars. \\
PopGr & State population growth rate over past year. \\
Renter & Percentage of population that rents their home. \\
Hours & Hours of prelicensing coursework required for salesperson's license. \\
Experience & Years of experience required before applying for full broker's license. \\
CEReq & Annual hours of required continuing education coursework. \\
Precip & Number of days per year of precipitation in largest city in state. \\
Complaints & Complaints filed against brokers as percent of house sales. \\
Bond & One if state requires brokers to be bonded, zero otherwise. \\
EandO & One if state requires errors and ommisions insurance, zero otherwise. \\
Black & Percentage of state population that is black. \\
DualAgency & One if state allows dual agency, zero otherwise. \\
\hline
\end{tabular}


Table 2: Summary Statistics. Data are across states (including the District of Columbia) and the years 1998-2005. The first panel contains summary statistics on 360 observations used in the 2SLS regression analysis of Table 2, and the second panel summarizes 326 observations used in the regression analysis of Table 3. Income data are from the Occupational Employment Statistics program of the Bureau of Labor Statistics. Data on the number of brokers, licensing requirements, complaints, and other broker characteristics are from the Association of Real Estate License Law Officials. House sales data are from the National Association of Realtors, house price data are from the Office of Federal Housing Enterprise Oversight. State GDP data are from the Bureau of Economic Analysis. Weather data are from the National Ocieanic and Atmospheric Administration. Other state characteristics are from the Census Department.

\begin{tabular}{lrrrr}
\hline Variable & Mean & Std. Dev. & Min & Max \\
\hline Income & 44.90 & 10.89 & 24.80 & 107.46 \\
Brokers & 47.04 & 21.73 & 0.49 & 158.70 \\
GDPGr & 2.50 & 2.77 & -6.47 & 11.63 \\
GDPPC & 39.39 & 13.44 & 25.45 & 150.36 \\
Urban & 72.23 & 15.12 & 38.18 & 100.00 \\
MoveTime & 35.21 & 6.67 & 14.73 & 55.18 \\
Price & 281.01 & 80.48 & 165.35 & 618.33 \\
PopGr & 1.26 & 1.44 & -1.20 & 11.55 \\
Renter & 29.53 & 5.43 & 22.51 & 56.40 \\
Hours & 177.59 & 131.89 & 35.00 & 840.00 \\
Experience & 2.08 & 1.01 & 0.00 & 5.00 \\
CEReq & 8.41 & 4.37 & 0.00 & 24.00 \\
Precip & 108.07 & 26.92 & 26.00 & 155.00 \\
Complaints & 4.26 & 3.37 & 0.00 & 19.01 \\
Bond & 0.33 & 0.47 & 0.00 & 1.00 \\
EandO & 0.26 & 0.44 & 0.00 & 1.00 \\
Black & 0.11 & 0.12 & 0.00 & 0.60 \\
DualAgency & 0.91 & 0.28 & 0.00 & 1.00 \\
\hline
\end{tabular}


Table 3: Supply and Demand for Brokers. Three Stage Least Squares regression. The first panel is the estimated demand curve, and the second panel is the supply curve. The dependent variable for both equations is Brokers.

\section{Demand}

\begin{tabular}{lrrr}
\hline Variable & Estimate & t ratio & p value \\
\hline Intercept & 188.34 & 2.42 & 0.02 \\
Income & -6.30 & -2.70 & 0.01 \\
GDPGr & 0.56 & 0.68 & 0.49 \\
GDPPC & 0.45 & 1.97 & 0.05 \\
Urban & 1.18 & 4.67 & 0.00 \\
MoveTime & -2.22 & -2.92 & 0.00 \\
Price & 0.24 & 3.46 & 0.00 \\
PopGr & 3.27 & 1.70 & 0.09 \\
Renter & 1.45 & 1.33 & 0.19 \\
\hline
\end{tabular}

Supply

\begin{tabular}{lrrr}
\hline Variable & Estimate & t ratio & p value \\
\hline Intercept & -26.54 & -1.77 & 0.08 \\
Income & 2.64 & 8.73 & 0.00 \\
Hours & -0.01 & -1.33 & 0.18 \\
Experience & -5.37 & -3.58 & 0.00 \\
CEReq & -1.48 & -4.67 & 0.00 \\
Precip & -0.18 & -3.77 & 0.00 \\
\hline & & & \\
Observations & 360 & \\
Weighted R Squared & 0.57 &
\end{tabular}


Table 4: Complaints Against Brokers. Ordinary Least Squares regression. The dependent variable is Complaints, the number of complaints against brokers filed with the state real estate commission as a percentage of house sales.

\begin{tabular}{lrrr}
\hline Variable & Estimate & t ratio & p value \\
\hline Intercept & -1.16 & -1.01 & 0.31 \\
Urban & 0.05 & 3.57 & 0.00 \\
Price & 0.00 & 1.45 & 0.15 \\
PopGr & 0.68 & 5.58 & 0.00 \\
Hours & 0.00 & 0.80 & 0.43 \\
Experience & 0.12 & 0.66 & 0.51 \\
CEReq & -0.03 & -0.64 & 0.53 \\
Bond & -0.70 & -1.69 & 0.09 \\
EandO & -1.00 & -2.38 & 0.02 \\
Black & -0.81 & -0.55 & 0.59 \\
DualAgency & 0.46 & 0.72 & 0.47 \\
\hline
\end{tabular}

Observations 326

Adjusted R Squared $\quad 0.21$ 